\title{
A Comparative Study between the Outcome of Laparoscopic Repair and Open Repair of Pediatric Inguinal Hernia
}

\author{
Sharifuzzaman $\mathbf{M}^{1}$, Ali MA ${ }^{2 *}$, Hasina $\mathrm{K}^{3}$, Huq MA ${ }^{3}$ and Alam $\mathrm{MM}^{3}$ \\ ${ }^{1}$ Department of Pediatric Surgery, Dhaka Medical College \& Hospital, Bangladesh \\ ${ }^{2}$ Department of Pediatric Surgery, Jessore Medical College, Bangladesh \\ ${ }^{3}$ Dhaka Medical College \& Hospital, Bangladesh
}

Submission: April 12, 2018; Published: May 24, 2018

"Corresponding author: Ansar Ali, Assistant Professor, Department of Pediatric Surgery, Jessore Medical College \& Hospital, Jessore, Bangladesh, Email: drfaruquzzaman@yahoo.com

\begin{abstract}
Background: A hernia is a protrusion of a viscous or part of a viscous through an abnormal opening in the wall of its containing cavity. A variety of surgical technique have been discovered for pediatric inguinal hernia such as transperitoneal closure of the deep inguinal ring without opening the superficial ring and the transinguinal approach, ligation of hernial sac at the deep ring. The present study has been designed to compare the Laparoscopic repair and Open repair of pediatric inguinal hernia.

Methods: This prospective comparative interventional study was carried out in department of pediatric surgery, DMCH, Dhaka, during the period of January '09 to March '10. Total sixty patients were included in this study. Among them 30 patients in Group-L were repaired by laparoscopic procedure and another 30 patients in Group- 0 were repaired by open procedure. Both groups were followed-up for three months.

Results: among sixty patients early post-operative complications were almost same and there was no recurrence in any groups. It was found that pain relief is earlier in laparoscopic repair than open repair and also cosmoses. Moreover laparoscopy can detect the contralateral hernia or contralateral persistent process us vaginalis and able to repair it in the same setting.
\end{abstract}

Conclusion: laparoscopic repair of pediatric inguinal hernia seems to be a better technique than open repair with regards to early pain relief and cosmoses. By which contralateral inguinal hernia is detectable and repairable.

Keywords: Inguinal hernia; Laparoscopic repair; Open repair

\section{Introduction}

A hernia is a protrusion of a viscous or part of a viscous through an abnormal opening in the wall of its containing cavity. The incidence of inguinal hernia in children range from $0.8 \%$ to $4.4 \%$ and is higher in infant [1]. Boys are affected approximately six times more than girls. Reported sex ratio range from $3: 1$ to 10:1. The predominance of right sided hernia is well established (Right sided 60\%, left sided-30\% and bilateral-10\%).

Inguinal Hernia (IH) is one of the commonest conditions in pediatric surgical practice. The hall mark of an inguinal hernia in a child is a groin bulge, extending towards the top of scrotum, which is visible most frequently during periods of increased intra-abdominal pressure e.g. crying, straining.

A true IH will not resolve spontaneously, so surgical closure is always indicated. Because of the high risk of incarceration, particularly in young infants, repair should be performed expeditiously. Some reports suggested that $90 \%$ of complications can be avoided if repair is undertaken within 1 month of diagnosis. Most surgeons currently recommend repair of hernia soon after diagnosis. The first who referred to hernia repair in children is credited to Celsus, who in AD 25, recommended removal of the hernial sac and testes through a scrotal incision [2]. Pare recommended treatment of children hernia, however, the accurate description was made by Pott in 1756. Czery performed high ligation of hernial sac through the external ring [3].

A variety of surgical techniques have been discovered for pediatric transperitoneal closure of the deep ring inguinal herniotomy and include the transinguinal approach, ligation of hernial sac at the deep ring without opening the superficial 
ring. Modern hernia surgery began in the 19th century when an accurate understanding of the anatomy of the inguinal canal became available. In 1912, Turner documented that high ligation of sac was the only procedure necessary in most children. Owing to advances in pediatric laparoscopic instrumentation and increased experience with the technique of laparoscopy, a number of center routinely perform laparoscopic inguinal hernia repair in children Laparoscopic suturing and knot tying are becoming integral part of the skill that any laparoscopist must acquire. Intra corporeal suturing and knot tying for closure of the inguinal hernia may need a long learning curve [4].

Now this procedure is more feasible, less invasive and less painful. Moreover an advantage of this procedure is that, it allows detection and repair of the contra lateral hernia in same setting [5]. In our study we planned to find out the outcome of laparoscopic repair of inguinal hernia in terms of pain relief and cosmesis, in the pediatric age group.

\section{Materials and Methods}

A Prospective study was planned to make a comparison between the outcome of laparoscopic repair and open repair of pediatric inguinal hernia. The approval of hospital ethical committee was obtained after a detailed discussion of procedure and study design. A total of 60 patients of inguinal hernia were included for a period from January, 2009 to March 2010.

All patients selected for the study were divided in to two equal groups of 30 patients in each. All surgeries were performed after obtaining informed consent. Patients were operated on an alternate basis i.e. one patient by laparoscopic repair and next one by open repair of inguinal hernia. Information of patient's demographics, operative times, postoperative pain, complications, recurrence and cosmoses were collected. Patients were followed up for a period of 2 years postoperatively. All data were plotted on Microsoft Excel and analyzed with SPSS version 15.

\section{Technique}

\section{Both laparoscopic and open repair were done under general anesthesia}

In Group-L (laparoscopic repair) after antiseptic skin preparation of anterior abdominal sterile draping was done. A $5 \mathrm{~mm}$ umbilical port was made by open procedure and pneumoperitoneum was made with inflation of Carbon-di-Oxide keeping the pressure within 8-10mm Hg. A 300 Telescope with camera was then introduced into the abdominal cavity through this port and the patency of process us vaginalis through internal inguinal ring of affected side was detected. Under direct vision of the telescope two $5 \mathrm{~mm}$ working ports were introduced through left and right lower abdomen. Needle holder and Maryland forceps were introduced through these ports. A 3-0 vicryl with cutting body needle was then introduced into the abdominal cavity directly piercing the abdominal wall. After reducing the sac content (if present) with the help of forceps, purse-string suture around the internal ring was made by manipulating the working instruments. Intra corporeal knot was made and patent process us vaginalis was closed by tightening the knot. Further reinforcing knots were also made. Contra lateral side was inspected for patency of the process us vaginalis and if present, was repaired in the same procedure described above. All ports were then removed, gas was squeezed out, port wounds were closed by sub cuticular suture with 3-0 or 4-0 vicryl. Sterile dressings were then applied. Laparoscopic instrument used in this study was made by "Karl Storz" (Figure 1).

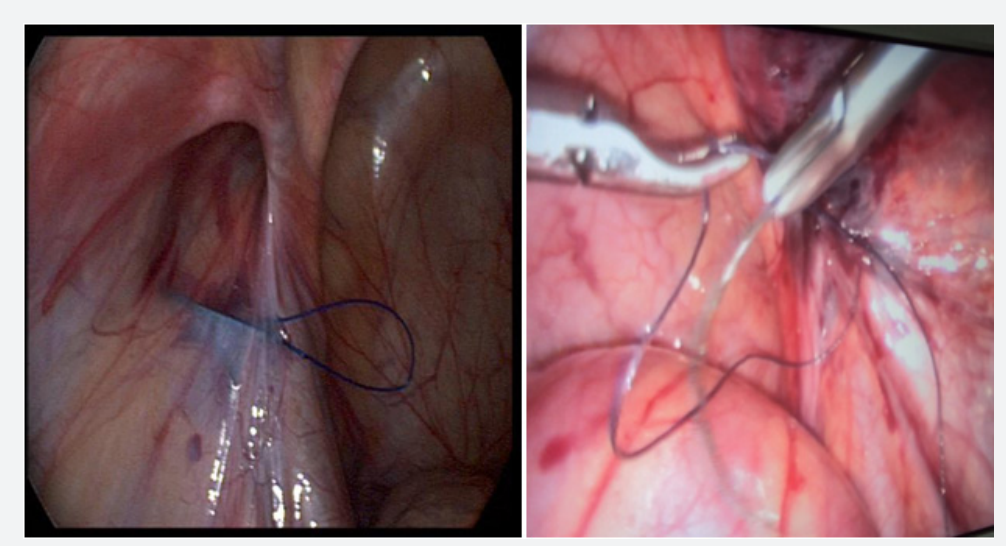

Figure 1: Laparoscopic repair inguinal hernia.

In Group-0, (Open repair) after antiseptic preparation of lower abdominal wall, a lower abdominal skin crease incision was made on the affected side, started just lateral to the pubic tubercle. After dissecting fascia of Camper, fascia of Scarpa and external oblique aponurosis from superficial to deep direction, the cremesteric muscle and fascia was swiped out by blunt dissection with forceps. Hernial sac was identified antero medial to the spermatic cord. It was carefully separated from testicular vessels and vas difference (in case of male) by blunt dissection. The sac was dissected proximally up to internal inguinal ring indicated by appearance of extra peritoneal fat. High ligation of neck of the sac was done at the level of the internal ring with 
3-0 or 4-0 vicryl and was excised distal to the knot. Redundant portion of sac was excised out if it was small enough or it was left in place if it was big. Inadvertent dissection of big distal portion of sac may results scrotal haematoma. The wound was closed in layers. Skin was closed by sub-cuticular suture with 3-0 or 4-0 vicryl. Sterile dressing was applied (Figure 2).
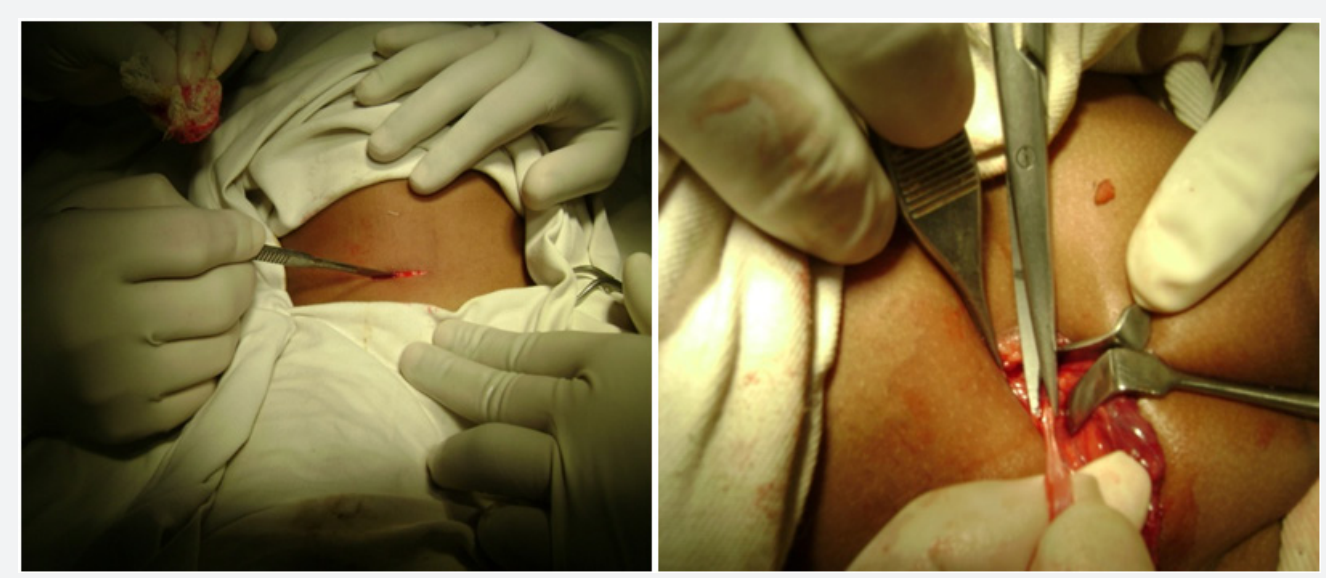

Figure 2: Open repair of inguinal hernia.

\section{Result}

This study was carried out from January 2009 to March 2010 in the Department of Pediatric Surgery, Dhaka Medical College Hospital, Dhaka. Total 60 patients of indirect inguinal hernia were grouped under 2 groups:
Group-L, (Laparoscopic repair, odd number), ( $\mathrm{n}=30)$.

Group-0, (Open repair, even number) $(n=30)$.

During this study period in the present series following observations were noted:

Tables (1-9).

Table 1: Age distribution of patients.

\begin{tabular}{|c|c|c|c|c|c|}
\hline \multirow{2}{*}{ Age(years) } & \multicolumn{2}{|c|}{ Group 0 Open Repair (n=30) } & \multicolumn{2}{c|}{ Group L Laparoscopic Repair (n=30) } & \multirow{2}{*}{ p Value } \\
\cline { 2 - 6 } & No & \% & No & -16.7 & $0.139^{\text {ns }}$ \\
\hline$£ 5$ & 10 & -33.3 & 5 & -56.7 & \\
\hline 510 & 17 & -56.7 & 8 & -26.7 & P value $^{\text {b }}$ \\
\hline$>10$ & 3 & -10 & & & $0.060^{\text {ns }}$ \\
\hline
\end{tabular}

${ }^{a}$ Chi square test, bUnpaired Student's 't' test ns $=$ Not significant

Table 2: Sex distribution in two groups of patients.

\begin{tabular}{|c|c|c|c|c|c|c|}
\hline \multirow{2}{*}{ Sex } & \multicolumn{2}{|c|}{ Group-L } & \multicolumn{2}{c|}{ Group-0 } & \multicolumn{2}{c|}{ Total } \\
\cline { 2 - 7 } & $\mathbf{n}$ & $\%$ & $\mathbf{n}$ & $\%$ & $\mathbf{n}$ & $\%$ \\
\hline Male & 26 & 86.67 & 27 & 90 & 53 & 88.33 \\
\hline Female & 4 & 13.33 & 3 & 10 & 7 & 11.67 \\
\hline Total & 30 & 100 & 30 & 100 & 60 & 100 \\
\hline
\end{tabular}

Total 53 patients of this series were male and 7 were female, among them in Group-L, out of 30 patients 26 were male and the rest were female, in Group-O out of 30 patients 27 were male and the rest were female.
Table 3: Side distribution in two groups of patient.

\begin{tabular}{|c|c|c|c|c|c|c|}
\hline & \multicolumn{2}{|c|}{ Group-L } & \multicolumn{2}{c|}{ Group-0 } & \multicolumn{2}{c|}{ Total } \\
\cline { 2 - 7 } & $\mathbf{n}$ & $\%$ & $\mathbf{n}$ & $\%$ & $\mathbf{n}$ & $\%$ \\
\hline Right & 21 & 70 & 19 & 63.33 & 40 & 66.67 \\
\hline Left & 5 & 16.67 & 8 & 26.67 & 13 & 21.66 \\
\hline Bilateral & 4 & 13.33 & 3 & 10 & 7 & 11.67 \\
\hline Total & 30 & 100 & 30 & 100 & 60 & 100 \\
\hline
\end{tabular}

In group-L, among 30 patients right sided hernia were 21, left sided hernia were 5 and 4 were bilateral. These bilateral hernias were started to repair as right sided disease, but laparoscopy detected the contra lateral sides and repaired. In group-O, among 30 patients right sided hernia were 19, left sided hernia were 9 and bilateral were 2 . 
Table 4: Comparison of mean operative time between the study subjects.

\begin{tabular}{|c|c|c|c|}
\hline Operative Times & Open Repair & $\begin{array}{l}\text { Laparoscopic } \\
\text { Repair }\end{array}$ & $P$ value \\
\hline $\begin{array}{l}\text { Unilateral } \\
\text { inguinal hernia }\end{array}$ & $(n=27)$ & $(n=26)$ & \multirow{3}{*}{$0.0001^{* * *}$} \\
\hline Mean $\pm S D$ & $35.07 \pm 5.14$ & $46.92 \pm 4.23$ & \\
\hline Range & 25.045 .0 & 40.055 .0 & \\
\hline $\begin{array}{c}\text { Bilateral inguinal } \\
\text { hernia }\end{array}$ & $(n=3)$ & $(n=4)$ & \multirow{3}{*}{$0.055 n s$} \\
\hline Mean $\pm S D$ & $70.00 \pm 5.00$ & $63.00 \pm 2.45$ & \\
\hline Range & 65.075 .0 & 60.065 .0 & \\
\hline
\end{tabular}

Unpaired Student's 't' test

$\mathrm{ns}=$ Not significant, ${ }^{* * *}=$ Significant at $\mathrm{P}<0.001$

Table 5: Children's Hospital-of-Eastern Ontario Pain Score (CHEOPS) (McGrath et al. [6]).

\begin{tabular}{|c|c|c|c|}
\hline Crying & None & Moaning/crying & Screaming \\
\hline $\begin{array}{c}\text { Facial } \\
\text { expression }\end{array}$ & Smiling & Composed & Grimace \\
\hline $\begin{array}{c}\text { Verbal } \\
\text { expression }\end{array}$ & Positive & $\begin{array}{c}\text { None or other } \\
\text { complaints }\end{array}$ & $\begin{array}{c}\text { Complaints of } \\
\text { pain }\end{array}$ \\
\hline Torso & Neutral & $\begin{array}{c}\text { Shifting/tense/ } \\
\text { upright }\end{array}$ & Restrained \\
\hline Legs & Neutral & $\begin{array}{c}\text { Squirming/kicking/ } \\
\text { drawn-up }\end{array}$ & Restrained \\
\hline
\end{tabular}

Patients with CHEOPS $\geq 4$ were given specified doses of Diclofenac Sodium, $1.5 \mathrm{mg} / \mathrm{kg} /$ dose per rectal.

Table 6: Comparison of mean doses of Diclofenac Sodium Unpaired Student's 't' test.

\begin{tabular}{|c|c|c|c|}
\hline & $\begin{array}{c}\text { Open Repair } \\
(\mathbf{n}=\mathbf{3 0})\end{array}$ & $\begin{array}{c}\text { Laperoscopic Repair } \\
(\mathbf{n = 3 0 )}\end{array}$ & P value \\
\hline Mean \pm SD & $4.30 \pm 0.70$ & $2.43 \pm 0.94$ & \multirow{2}{*}{$0.0001^{* * *}$} \\
\hline Range & 3.06 .0 & 1.04 .0 & \\
\hline
\end{tabular}

*** = Significant at $\mathrm{P}<0.00$

Table 7: Comparison of mean wound appearance score (VAS: Visual Analog Score) between the study groups.

\begin{tabular}{|c|c|c|c|}
\hline VAS & $\begin{array}{c}\text { Open Repair } \\
(\mathbf{n = 3 0 )}\end{array}$ & $\begin{array}{c}\text { Laperoscopic Repair } \\
(\mathbf{n = 3 0 )}\end{array}$ & P value \\
\hline Mean \pm SD & $75.67 \pm 6.12$ & $90.00 \pm 5.25$ & \multirow{2}{*}{$0.0001^{* * *}$} \\
\hline Range & 65.085 .0 & 80.0100 .0 & \\
\hline
\end{tabular}

Unpaired Student's 't' test

$* * *=$ Significant at $\mathrm{P}<0.001$

Table 8: Comparison of Complications in two study groups.

\begin{tabular}{|c|c|c|}
\hline Complications & Group O (n=30) & Group L (n=30) \\
\hline a) Port site hematoma & 0 & 2 \\
\hline b) Stitch abscess & 2 & 1 \\
\hline c) Skin sensitivity to dressing & 1 & 2 \\
\hline d) Post operative vomiting & 2 & 1 \\
\hline e) Transient hydrocele & 1 & 1 \\
\hline
\end{tabular}

Table 9: Comparison of recurrence in two study groups.

\begin{tabular}{|c|c|c|}
\hline & \multicolumn{2}{|c|}{ Recurrence $(\mathbf{n = 6 0 )}$} \\
\hline & $\mathbf{n}$ & $\mathbf{\%}$ \\
\hline Group-L & 0 & 0 \\
\hline Group-O & 0 & 0 \\
\hline
\end{tabular}

In both the groups there was no recurrence.

\section{Discussion}

This was a study of pediatric hernia repair to compare laparoscopic with open methods by conducting a prospective study at a single institution. Multi center studies entail a certain failure rate because of the bias of the surgeon and variations in the level of surgical expertise across centers [7], whereas singlecenter trials have the advantages of clearly defined procedures and uniform postoperative care and analgesia [8] .The study on 60 patients was adequate to show a statistical difference.

Many of the initial attempts at laparoscopic hernia repair in adults did not adhere to the established principles followed for open surgery [9]. For pediatric hernias, high ligation of the hernia sac is all that is required for correction [10]. In normal situations, recurrence after an open procedure may be attributed to a failure to ligate the sac high enough at the internal ring, injury to the floor of the inguinal canal due to operative trauma, failure to close the internal ring in girls, or postoperative wound infection and hematoma [11]. Our laparoscopic technique for the repair of IH has proven to be a safe method, when performed carefully that can prevent or avoid all these possible causes of recurrence [12].

No recurrences were found in any of our group L patients after a mean follow-up period of 3 months. Our group 0 had no recurrences either. In the literature, the recurrence rate for pediatric IH repair has been reported to be $1-2.5 \%$, and recurrences are more frequent in patients operated on by junior surgeons or surgeons with no specific training in pediatric surgery [13]. There is no significant age difference in this study. The three-port technique of the LR enables the repair of bilateral hernias. Insertion of the three ports takes some extra time, so for cases of unilateral hernia, the group L had a longer operative time than the group 0 . However, comparatively less time was required for repairing bilateral hernia in group L, as no extra time for instrumental setting was required.

Laparoscopic hernia repair resolves the question of whether contra lateral exploration is necessary in children with IH [14]. The rate of contra lateral patent process us vaginalis repair in our patients was $13.33 \%$. One may argue that not all cases of patent process us vaginalis will develop into hernias. Open repaired patient presenting with unilateral hernias were found on follow-up to have developed contra lateral hernias. Because these patients had been treated with the open technique, rather than laparoscopic ally, there was no knowledge or treatment of the contra lateral side. The number of contra lateral hernias in this group may increase further with time because, pediatric 
inguinal hernia is the result of a patent process virginals. Though the rate of detecting CPPV was significantly low $(p<0.001)$ in this study conducted with a small sample, in a large sample study it would be significant and be established as a excellent advantage of this procedure.

Objective behavioural and physiological parameter scoring systems was used in the present study. Patients with CHEOPS $\geq 4$ were given specified doses of Diclofenac Sodium, 1.5mg/ $\mathrm{kg} /$ dose per rectally, and the dose was repeated every 8 hours, if necessary. There was no age difference between the two groups. The group L required significantly lesser amount of analgesics than group 0 , indicating that laparoscopic repair was less painful. The parent's assessments also indicated that the children recovered faster in the group L.

The scoring system for wound appearance used in this study was "Visual Analog Scale"(VAS). Parents of the patients were explained and demonstrated about worst possible scar and almost normal skin and were asked to score 0 and 100 respectively for these two extreme and other possible scores for wound appearance in between these. Most of the parents of the patients in the group L gave excellent scores to their children's wound cosmists according to Visual Analogy Scale; this percentage was significantly higher than that for the group 0 patients. Wound complications were minimal in both groups.

In conclusion, in pediatric patients with IH, the outcome of laparoscopic repair is superior to open repair with regard to postoperative pain, recovery, and cosmists. Laparoscopic hernia repair also enables the detection of contra lateral hernias so that they can be repaired in the same operative setting.

\section{Conclusion}

Laparoscopic repair is superior with regard to early pain relief and cosmesis, but needs to be evaluated on wider group of patients and long period of follow up.

\section{References}

1. Philip LG, Scott CB (2006) Inguinal hernias and Hydroceles Pediatric Surgery ( $6^{\text {th }}$ edn), Mosby Elsevier, Philadelphia, USA, pp. 1172-1189.

2. Niki S, Papavramidou, Aletrus HC (2005) Treatment of hernia in the writings of Celsus (First Century AD). World J Surg 29(10): 1343-1347.

3. Scott A, Engum JL, Grosfeld MD (2006) 'Hernias in children.' Operative Pediatric Surgery, ( $6^{\text {th }}$ edn), Oxford University Press: Edward Arnold Publishers, London, pp. 237-257.

4. Shalaby R, Ahmed D (2002) Needlescopic inguinal hernia repair in children. Pediatr Surg Int 18(2-3): 153-156.

5. Chan KL, Tam PKH (2003) A safe laparoscopic technique for the repair of inguinal hernias in boys. J Am Coll Surg 196(6): 987-989.

6. Mc Grath PJ, Johnson G, Goodman JT (1985) CHEOPS: A behavioral scale for rating postoperative pain in children. Pain Res 9: 395-402.

7. Ehrlich PF, Newman KD, Haase GM, Lobe TE, Wiener ES, et al. (2002) Lessons learned from a failed multi-institutional randomized controlled study. J Pediatr Surg 37(3): 431-436.

8. Majeed AW, Troy G, Nicholl JP (1996) Randomised, prospective, single-blind comparison of laparoscopic versus small incision cholecystectomy. Lancet 347(9007): 989-994.

9. Lau WY (2002) History of treatment of groin Hernia. World J Surg 26(6): 748-759.

10. Skoog SJ, Conlin MJ (1995) Pediatric hernias and hydroceles. Urol Clin North Am 22(1): 119-130.

11. Grosfeld JL, Minnick K, Shedd F, West KW, Rescoria FJ, et al. (1991) Inguinal hernia in children: factors affecting recurrence in 62 cases. J Pediatr Surg 26(3): 283-287.

12. Cheung TT, Chan KL (2003) Laparoscopic inguinal hernia repair in children. Ann Coll Surg HK 7: 94-96.

13. Carneiro PM (1990) Inguinal herniotomy in children. East A Med J 67(5): 359-364.

14. Surana R, Puri P (1993) Is contralateral exploration necessary in infants with unilateral inguinal hernia? J Pediatr Surg 28(8): 1026-1027.

\section{Your next submission with JuniperPublishers will reach you the below assets}

- Quality Editorial service

- Swift Peer Review

- Reprints availability

- E-prints Service

- Manuscript Podcast for convenient understanding

- Global attainment for your research

- Manuscript accessibility in different formats

( Pdf, E-pub, Full Text, audio)

- Unceasing customer service

Track the below URL for one-step submission https://juniperpublishers.com/online-submission.php 